\title{
ANALYSIS OF MAXIMUM DEFORMATION OF HIGH RISE BUILDINGS WITH OUTRIGGER SYSTEM AGAINST WIND LOAD
}

\author{
Resti Nur Arini ${ }^{1}$, Fadli Kurnia ${ }^{1}$,Dwi Ariyani ${ }^{1}$ Soni $^{1}$ \\ ${ }^{1}$ Civil enggineering, Engineering Faculty, Pancasila University, Jakarta Indonesia \\ E-mail: resti.nurarini@univpancasila.ac.id
}

Received $8^{\text {th }}$ October 2020, Accepted $27^{\text {th }}$ October 2020

\begin{abstract}
Outrigger structural systems are quite effective using the lateral loads on tall buildings, one of the main benefits of utilization outrigger is that it can reduce deformation and the danger of inter-story drift caused by lateral loads acting on the building. In this case, wind loads will be viewed as a lateral load because the wind load acting on tall buildings can also cause deformation of the building. The implementation of the outrigger system is viewed from different positions to see the deformation that occurs and the placement of the maximum location. The results of the analysis of wind loads reviewed on these buildings have proven that the use of outriggers in buildings can reduce displacement by $19.58 \%$, and inter-storey drifts by $13.24 \%$, which is applied in a position of $1 / 2$ of the building height. The optimum location of the outrigger installation can also be determined by calculating the analysis of the maximum deflection that occurs on the 40th floor.
\end{abstract}

Keywords : Lateral Loads, Wind Loads, Outrigger, Double Truss, Single Truss, Displacement, Inter Story Drift, Maximum Deformation 


\section{INTRODUCTION}

The outrigger system is usually used as one of the effective structural systems to control lateral loads (Kogilgeri \& Shanthapriya, 2015). When small or medium lateral loads act on a structure, either wind or earthquake loads that cause a response to the building, structural and nonstructural damage can be avoided, even though an engineer can predict the damage caused by the working force (W.M.Ho, 2017). The outrigger system is generally used in high-rise buildings that are also located in areas that are earthquake zones or where wind loads have a sufficient impact on the building so that the outrigger is very effective in reducing lateral deflection that occurs. (Zhou, et al., 2016).

The column for the outer part of the high-rise building is connected to a core wall in the middle of the building with outrigger bars that are very rigid on one or more levels. When lateral loads act on the building, the bending in the core wall rotates the rigid outriggers that are also connected to the core wall and affects the tension and compression of the column. (Faimun, 2017).

The outrigger, which has functions to withstand the lateral forces, has an effect on building deformation, one of which is the wind load. In addition to earthquake loads, wind loads need to be considered in high-rise buildings, where wind pressure will hit high-rise buildings that have angles or openings that will increase the correlation of wind forces in multiple directions. (Miyashita, et al., 1993).

The outrigger system is one of the lateral loadbearing and stiffening systems which is generally in the form of a steel profile, it can also be concrete or composite. In this concept, the outrigger functions as a lateral load-bearing that connect the core wall with the column which is located on the outer part of the building. The core wall in question can be a shear wall or a braced frame according to the plan (Kogilgeri \& Shanthapriya, 2015).

The core combined with the outrigger may be located in the middle with the outrigger extended on both sides (Figure 1), or it may be located on one side of the building with the outrigger extending to the building column on one side (Figure 2 ), (Taranath, 2012).

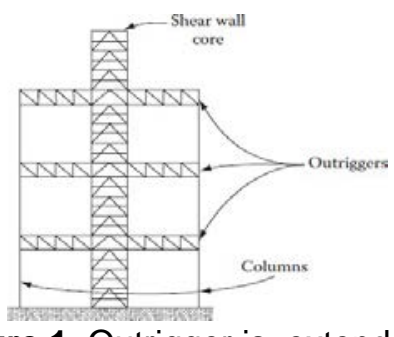

Figure 1. Outrigger is extended on both sides Source : (Taranath, 2012)

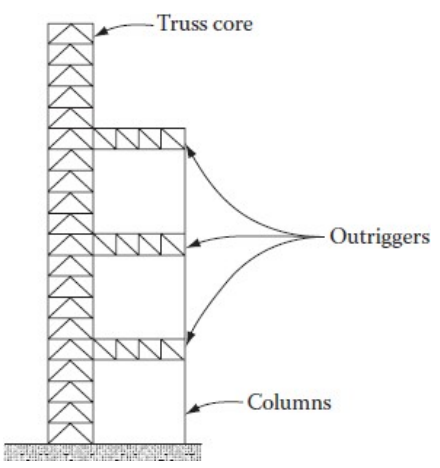

Figure 2. Outrigger is extended on one side Source : (Taranath, 2012)

The outrigger is a stiffener structure in the form of arms tied to the core wall to the outermost column of the building. The principle is like a sailing ship where the mast is the core, the crosses of the sail are the outrigger. In other words, this system utilizes the width of the building to maximize stiffness because the outrigger itself can provide resistance to rolling moments from earthquake loads or wind pressure to make the building more stable.
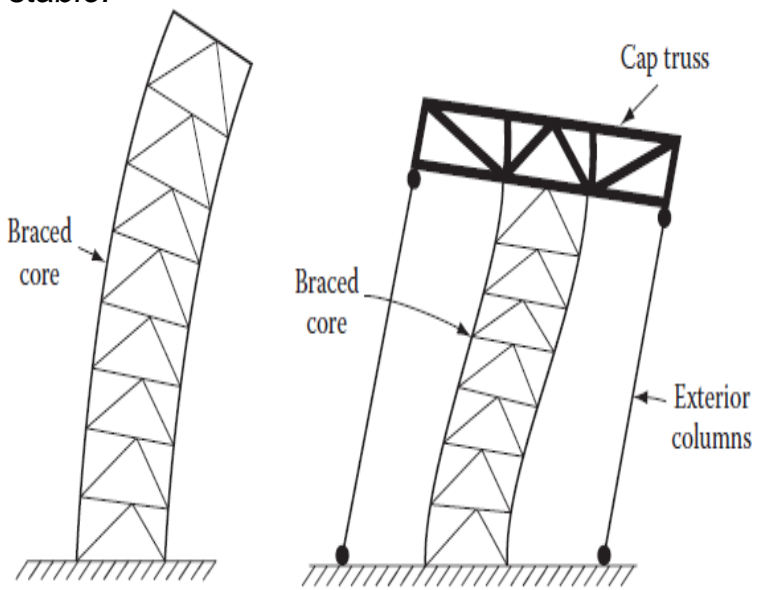

Figure 3. The brace and the brace core, Exterior Column, and Cap Truss

Source : (Taranath, 2012)

When the outrigger has been installed and is properly effected, it can provide structural and functional advantages for the overall building planning, namely, the moment on the core wall and the increase in deformation that occurs can be reduced through rotating moments acting on the core wall at each outrigger intersection. This moment results from a force pair on the outermost column connected to the outrigger (Choi, et al., 
2012) (Goman, 2016).

Because the main problem lies in the limited space for loading and movement due to the placement of the outrigger, usually the floor that uses the outrigger is maximized as best as possible so as not to become part of a magnificent and tall building that does not function at all. (Choi \& Joseph, 2012).

In addition to earthquake loads, the problem of wind loads is also a major issue in the planning of high-rise buildings because it affects the strength of the building and also concerns the serviceability of the building users (Miyashita, et al., 1993) (Lam, et al., 2008).

It may be impossible to understand all wind problems and predict scientific wind characteristics. This is due to the influence of wind loads on buildings that are dynamic and influenced by several environmental factors (Angerik, 2009). In tall buildings such as in big cities, the wind pressure will be greater on each surface of the wall so that wind pressure can damage parts on each side of the building (Lam, et al., 2008).

In the research an analysis was carried out to study the effect of outrigger to reduce deformation and inter-story drift caused by working wind loads and the maximum deformation that occurs to determine the optimum 1-floor position for the outrigger placement. So, placing the outrigger in the right position will help reduce the deformation that occurs in tall buildings.

From the previous background, this study intends to analyze the maximum deformation caused by wind pressure acting on tall buildings and, while the points to be discussed as follows:

1. Deformation of 5 outrigger structure models placed in different positions:

2. Inter story drift, which is the deformation difference for each floor of the 5 structural models.

3. The optimum location for placing the outrigger in high-rise buildings.

\section{METHOD}

In conducting a comparative analysis of the placement of an outrigger system in a high-rise concrete building in terms of the response to this wind load, the steps taken can be described in the flow chart in Figure 4:

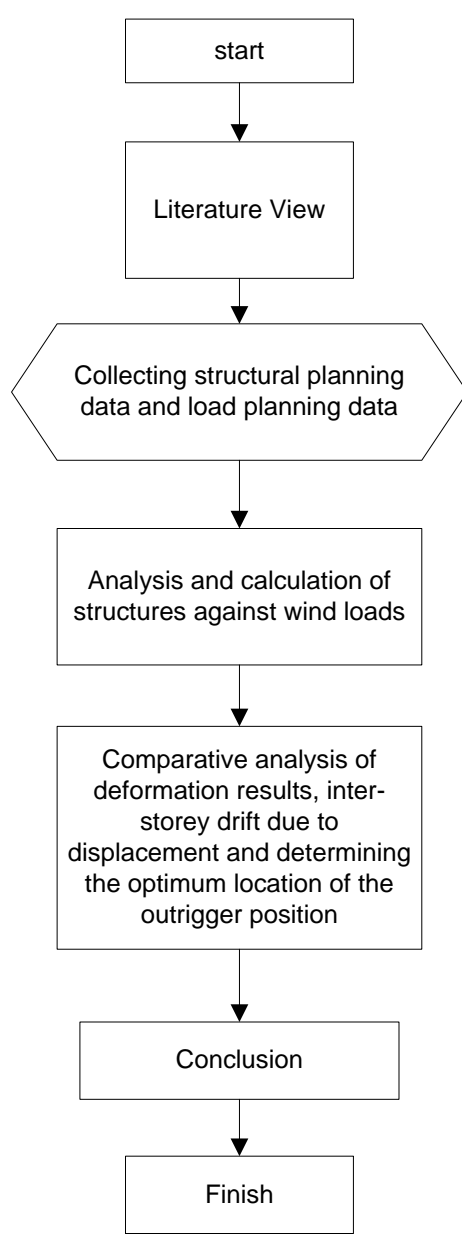

Figure 4. Research flow chart

\section{Wind load calculation}

Extensive research is being carried out to obtain predictions of the action of wind loads on high-rise buildings. The building code used is only a static approach that overshadows the dynamic action of wind load characteristics. The value of wind pressure is an equation function of the annual wind speed in units of mph (miles per hour), 30 feet ( $\mathrm{ft}$ ) above the ground over a period of 50 years.

Using formulas and methods, the wind pressure generated by the wind in a high-rise building can be calculated using a formula (Schueller, 2001).

$$
p=0.002558 C_{D} V^{2}
$$

where:

$p=$ pressure on the face of the building (psf)

$C D=$ coefficient of shape

$\mathrm{V}=$ maximum speed (mph)

The coefficient of CD shape depends on the shape of the building and the shape of the roof of the building. For a rectangular tall building, the $C D$ value is 1.3 , which is the sum of the wind pressure effect of 0.8 and the suction effect of the wind 0.5 . The value of wind pressure can be obtained from the building height equation. 
In this case, the equation is given to a building that is $30 \mathrm{ft}(9,144 \mathrm{~m})$ above ground level with a wind speed of $75 \mathrm{mph}(33.5 \mathrm{~m} / \mathrm{s})$ which results in:

$$
p=0.002558(1,3)(75)^{2} \approx 18 p s f
$$

To produce a building code for a rectangular tall building with a wind speed of $75 \mathrm{mph}(33.5 \mathrm{~m} / \mathrm{s})$ which has been described in the graph as follows:

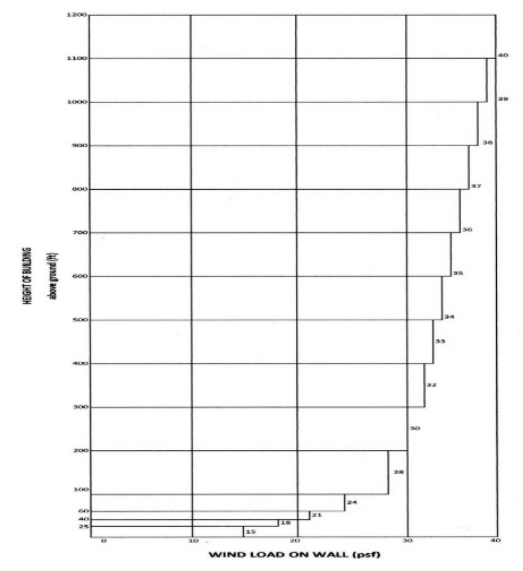

Figure 5. Wind Load Graph Base on High of Building

Source : (Schueller, 2001)

\section{Calculations on High-rise Buildings}

\section{Wind Load}

The calculation of wind load was performed by using the wind load graph in Figure 5 the reading of the graph (psf) will be multiplied by the height of the floor concerned ( $\mathrm{ft}$ ) and multiplied by the length of the building span (ft). The result of the wind load will be calculated in kips

The moment of resistance generated by the weight of the building itself is by using the formula:

$$
M_{\text {res }}=W_{D L}\left(\frac{D}{2}\right)
$$

Where :

Mres $=$ moment of resistance $(\mathrm{ft} \mathrm{k})$

WDL = dead load (kips)

$\mathrm{D}=$ span of building width $(\mathrm{ft})$

In addition, the torque that occurs can be calculated by the

formula: $M_{\text {rot }}=\sum W_{i} h_{i}$

Where :

Mrot $=$ rotational moment $(\mathrm{ft} \mathrm{k})$

$\mathrm{Wi}=$ wind load at height $\mathrm{i}$ (kips)

$\mathrm{hi}=$ center line of height $\mathrm{i}(\mathrm{ft})$

So that from these two moments, a safety factor can be obtained to overcome the rotation. The formula is:

$S F=\frac{M_{\text {res }}}{M_{\text {rot }}}>1.5$

Where :

$\mathrm{SF}=$ safety factor
Mres $=$ moment of resistance $(\mathrm{ft} \mathrm{k})$

Mrot $=$ rotational moment $(\mathrm{ft} \mathrm{k})$

\section{Stiffness}

The value of the stiffness $\mathrm{K}$ can be obtained from the force $p$ acting on each outer column of the building with the equation $p=A E \delta / L$; Where $\delta$ $=d / 2$, thus producing an equation (Taranath, 2012) :

$\rho=\frac{A E}{L}\left(\frac{d}{2}\right)$

and the contribution of equation (5) to the stiffness formula will be:

$$
K=\rho_{i} d=\frac{A_{i}}{L} \frac{d^{2}}{2}
$$

Where :

$\mathrm{K}=$ stiffness value

$A=$ area of the column

$E=$ modulus of elasticity of the core wall

$\mathrm{d}=$ distance from column to column

$\mathrm{L}=$ height of the building

\section{Deformation}

To compare the deformation results in tall buildings using an outrigger, the deformation calculation will be divided into 5 structural models. Five examples of the outrigger installation model are as follows (Taranath, 2012):

1. The first structural model of this building analysis without using an outrigger. Displacement in the first structural model can be directly determined analytically using the equation:

$$
\Delta_{1}=\frac{W L^{3}}{8 E I}
$$

Where :

$\Delta=$ displacement on the highest floor

$\mathrm{W}=$ wind load per building height

$\mathrm{L}=$ height of the building

$\mathrm{E}=$ modulus of elasticity of the core wall

$\mathrm{I}=$ moment of inertia of the core wall

2. The second structural model, the outrigger is installed on the highest floor of the building ( $x$ $=0$ or $Z=L$ ) which causes the top floor to become a rigid floor. The $x$ value is the location where the outrigger is placed as measured from the top of the building while the $Z$ value is the height at which the outrigger is installed as measured from the ground.

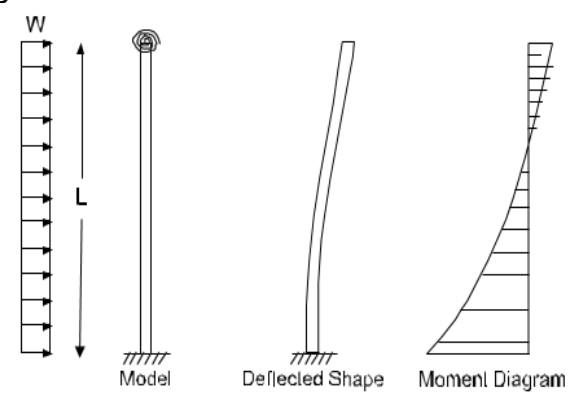

Figure 6. Modelling position of Outrigger $x=0$ Source : (Taranath, 2012) 
The equation of the angular rotation that occurs due to the installation of the outrigger can be written in the equation:

$$
\theta_{W}-\theta_{S}=\theta_{L}
$$

where:

$\theta_{W} \quad=$ rotation of cantilever due to wind load laterally when $\mathrm{Z}=\mathrm{L}$

$\theta_{S} \quad=$ rotation of the cantilever due to stiffness

$\theta_{L} \quad=$ the final rotation of the cantilever when $\mathrm{Z}=\mathrm{L}$

The negative sign indicates rotation or rotation that occurs due to stiffness in the opposite direction to rotation or rotation due to external loads (wind). For the cantilever of tall buildings with a moment of inertia I and modulus of elasticity $E$ and obtaining evenly distributed wind loads laterally $\mathrm{W}$, then:

$\theta_{W}=\frac{W L^{3}}{6 E I}$

If $\mathrm{M} 2$ and $\mathrm{K} 2$ represent the moment and stiffness in the second structural model, namely when the outrigger is placed at the top of the building or $Z$ $=\mathrm{L}$, then equation (8) can be broken down into :

$$
\frac{W L^{3}}{6 E I}-\frac{M_{2} L}{E I}=\frac{M_{2}}{K_{2}}
$$

So that the M2 moment becomes:

$$
M_{2}=\frac{\frac{W L^{2}}{6 E I}}{\frac{1}{K_{2}}+\frac{L}{E I}}
$$

Displacement $\Delta 2$ at the top of the building can be obtained by superposing the deflection of the cantilever due to the uniform wind load $\mathrm{W}$ and deflection due to the moment of outrigger effect so that it will be obtained:

$\Delta_{2}=\frac{W L^{4}}{8 E I}-\frac{M_{2} L^{2}}{2 E I}$

Thus becoming:

$$
\Delta_{2}=\frac{L^{2}}{2 E I}\left(\frac{W L}{4} M_{2}\right)
$$

3. In the third structural model, the outrigger is installed at position $3 / 4$ from the height of the building, namely at position $x=0.25 \mathrm{~L}$ or $\mathrm{Z}=$ $0.75 \mathrm{~L}$.

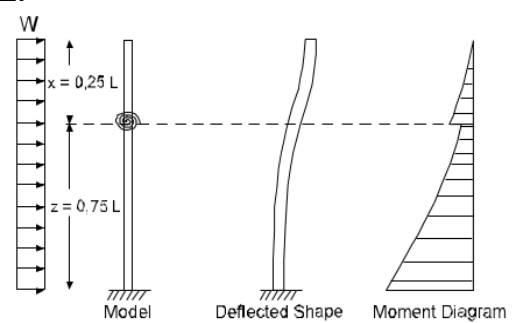

Figure 7. Modelling position of Outrigger

$$
x=1 / 4 \mathrm{~L}
$$

Source : (Taranath, 2012)

The Y-lateral deflection caused by even lateral loads is

$$
y=\frac{W}{24 E I}\left(x^{4}-4 L^{3} x+3 L^{4}\right)
$$

By differentiating $\mathrm{y}$ to $\mathrm{x}$, we get the equation for:

$\frac{d_{y}}{d_{x}}=\frac{W}{6 E I}\left(x^{3}-L^{3}\right)$

Substitute the value of $x=1 / 4 \mathrm{~L}$ into equation

(II.14) to produce:

$\frac{d_{y}}{d_{x}}\left(Z=\frac{3 L}{4}\right)=\frac{W}{6 E I}\left(\frac{L^{3}}{64}-L^{3}\right)$

And the result becomes:

$\frac{d_{y}}{d_{x}}=\frac{W L^{3}}{6 E I} \times \frac{63}{64}$

$\mathrm{M} 3$ and $\mathrm{K} 3$ represent moments and stiffness in the model of a third structure which is when the outrigger is placed on the $3 / 4$ of the height of the building or $Z=3 / 4 \mathrm{~L}$, the equation (8) can be decomposed into :

$\frac{\mathrm{WL}^{3}}{6 \mathrm{EI}}\left(\frac{63}{64}\right)-\frac{\mathrm{M}_{3}}{\mathrm{EI}_{\mathrm{I}}}\left(\frac{3 \mathrm{~L}}{4}\right)=\frac{\mathrm{M}_{3}}{\mathrm{~K}_{3}}$

Given the value of $\mathrm{K} 3=4 \mathrm{~K} 2 / 3$, the $\mathrm{M} 3$ equation can be written:

$M_{3}=\left(\frac{\frac{W^{3}}{6 E I}}{\frac{1}{\mathrm{~K}_{2}}+\frac{\mathrm{L}}{\mathrm{EI}}}\right) \frac{\frac{63}{64}}{\frac{3}{4}}$

So that M3 will be:

$$
\mathrm{M}_{3}=\left(\frac{\frac{\mathrm{WL}^{2}}{6 \mathrm{EI}}}{\frac{1}{\mathrm{~K}_{2}}+\frac{\mathrm{L}}{\mathrm{EI}}}\right) 1.31
$$

Based on the $M 2$ value in equation 11, equation (2.17) can also be written:

$$
\mathrm{M}_{3}=1.31 \mathrm{M}_{2}
$$

The displacement $\Delta 3$ when $Z=3 / 4 \mathrm{~L}$ can be obtained from the equation

$$
\Delta_{3}=\frac{W L^{4}}{8 E I}-\frac{M_{3} 3 L}{4 E I}\left(L-\frac{3 L}{8}\right)
$$

And the value of $\Delta 3$ can be obtained by equations:

$$
\Delta_{3}=\frac{L^{2}}{2 E I}\left(\frac{W L}{4}-1.23 M_{2}\right)
$$

4. In the fourth structural model, the outrigger is installed at $1 / 2$ of the building height, namely at the position $\mathrm{x}=0.5 \mathrm{~L}$ or $\mathrm{Z}=0.5 \mathrm{~L}$.

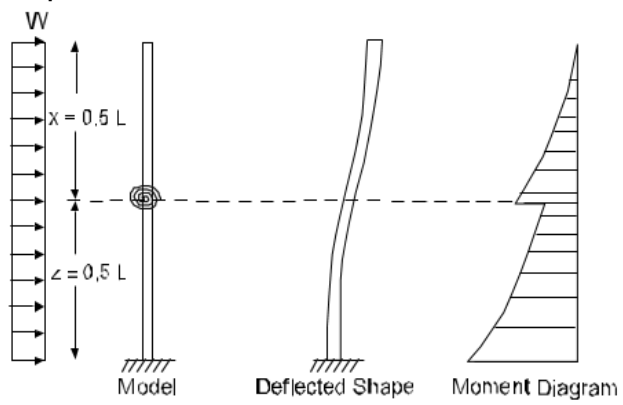

Figure 8. Modelling position of Outrigger $x=1 / 2 L$

Source : (Taranath, 2012)

The rotation due to the uniform load $W$ at $Z=1 / 2 L$ is equal to $7 \mathrm{WL} 3 / 48 \mathrm{E} \mathrm{I}$, so the rotation equation (II.8) will be:

$$
\frac{7 W L^{3}}{48 E I}-\frac{M_{4} L}{2 E I}=\frac{M_{4}}{K_{4}}
$$


M4 and K4 represent the moment and stiffness in the fourth structural model, namely when the outrigger is placed in the middle of the building height or $x=Z=1 / 2 L$. The stiffness value $K 4=2$ $\mathrm{K} 2$, then the equation M4 (20) can be broken down into:

$$
M_{4}=\left(\frac{\frac{W L^{2}}{6 E I}}{\frac{1}{K_{2}}+\frac{L}{E I}}\right) \times \frac{7}{4}
$$

Based on the M2 value in equation (11), equation (21) can also be written:

$M_{4}=1.75 M_{2}$

And the displacement $\Delta 4$ when $Z=1 / 2 \mathrm{~L}$ can be obtained from the equation:

$\Delta_{4}=\frac{W L^{4}}{8 E I}-\frac{M_{4} L}{2 E I}\left(L-\frac{L}{4}\right)$

Will be:

$\Delta_{4}=\frac{L^{2}}{2 E I}\left(\frac{W L}{4}-1.31 M_{2}\right)$

5. In the last structural model in modeling the outrigger, the structure is installed at $1 / 4$ of the building height, namely at the position $x=0.75 \mathrm{~L}$

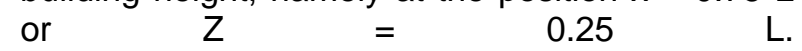

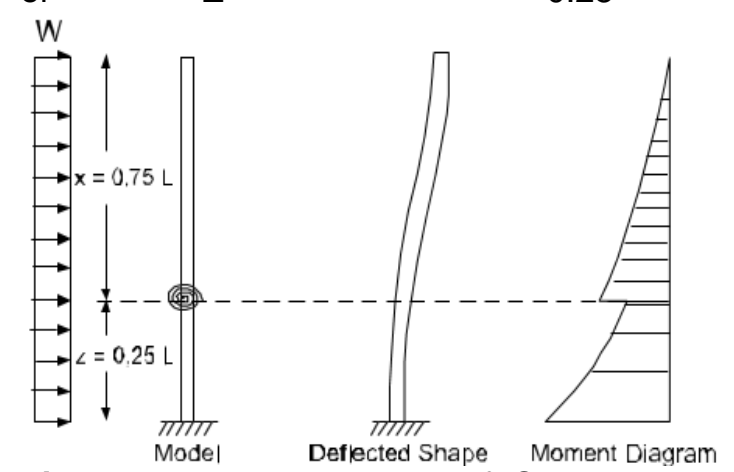

Figure 9. Modelling position of Outrigger

$$
x=3 /{ }_{4} L
$$

Source : (Taranath, 2012)

The rotation due to the outside load is evenly distributed $W$ at $Z=1 / 4 \mathrm{~L}$ is differentiated and is equal to $W$ L3 / $6 \mathrm{E} \mathrm{I} \mathrm{(37/64),} \mathrm{so} \mathrm{the} \mathrm{rotation}$ equation (2.7) will be:

$\frac{W L^{3}}{6 E I}\left(\frac{37}{64}\right)-\frac{M_{5} L}{4 E I}=\frac{M_{5}}{K_{5}}$

M5 and K5 represent the moment and stiffness equation in the fourth structural model, namely the installation of the outrigger at $1 / 4$ of the height of the building, namely at $x=3 / 4 \mathrm{~L}$ or $Z=1 / 4 \mathrm{~L}$. The stiffness value of $\mathrm{K} 5=4 \mathrm{~K} 2$, then the equation M5 (24) can be described and after calculating and substituting the $\mathrm{M} 2$ value (10), it will become:

$M_{5}=2.3 M_{2}$

And the displacement $\Delta 5$ when $x=3 / 4 \mathrm{~L}$ or $Z=1 / 4 \mathrm{~L}$ can be obtained from the equation:

$\Delta_{5}=\frac{W L^{4}}{8 E I}-\frac{M_{5} L}{4 E I}\left(L-\frac{L}{8}\right)$
Optimal Location of Outrigger Placement in High-rise Buildings

In the illustration and modeling of tall building structures, it was previously known that binding the outer column to the corewall is a function of two characteristics, namely the stiffness caused by

$$
\Delta_{5}=\frac{L^{2}}{2 E I}\left(\frac{W L}{4}-M_{2}\right)
$$

Outrigger and angular rotation that occurs due to the location of the outrigger placement against evenly distributed outside loads (wind) (Pesik, et al., 2018).

The stiffness of the outrigger will reach its minimum value when placed on the top floor. And the stiffness value will be maximum when placed on a lower floor, in this model it is at position $1 / 4$ of the building height. Meanwhile, the rotational rotation occurs as a result of the wind load which varies in value parabolically, from having a maximum value above to reaching a zero value below. Thus, from the standpoint of stiffness as well as considerations of the rotation that occurs, the location of the outrigger can be determined. And it is very clear that the optimum location for placing the outrigger is around the center of the building height.

With the assumption that the outrigger used is very rigid, then the optimum location of the outrigger placement can be obtained by calculus calculations. The first step is to use the equation for rotation at $x$, which is where the outrigger is placed from the top of the building.

$$
\begin{aligned}
\frac{W}{6 E I}\left(x^{3}-L^{3}\right) & -\frac{M_{x}}{E I}(L-x) \\
& =\frac{M_{x}}{K_{x}}
\end{aligned}
$$

where :

$W=$ wind load

$M_{x}=$ moment at $x$

$K_{x} \quad=$ outrigger striffnes at equal $\mathrm{x}$

With $\frac{A E}{(L-x)} \frac{d^{2}}{2}$

$L \quad=$ high building

$E \quad=$ elasticity modulus

I = inersia moment of core wall

$A \quad=$ the area of the column that ties the outrigger

$x=$ the location of the outrigger as measured from the top floor

$d \quad=$ distance column to column

Then, the peak deflection value on the building can be obtained from the $M x$ value with the equation:

$Y_{M}=\frac{M_{x}(L-x)(L+x)}{2 E I}$

The optimum location of the outrigger placement is the location where the YM deflection is maximum. Obtained from differentiating equation (28) with respect to $x$ and the result is zero. 


$$
\frac{d}{d x}\left[\frac{W\left(x^{3}-L^{3}\right)(L+x)}{12(E I)^{2}\left(\frac{1}{A E}+\frac{1}{E I}\right)}\right]=0
$$

So that it is obtained:

$$
4 x^{3}+3 x^{2} L-L^{3}=0
$$

\section{RESULTS AND DISCUSSION}

Deformation

Following are the results of deformation in buildings from wind load analysis:

$$
\begin{array}{lll}
W=2.7542 \times 107 \mathrm{~N} / \mathrm{m} \\
L=336.5 \mathrm{M} & \\
K=2.4094 \times 1011 \mathrm{Nm} \\
E=3.1528 \times 1010 \mathrm{~N} / \mathrm{m}^{2} \\
I=8899.586 & \mathrm{~m}^{4} \\
M_{2}=3.4628 \times 108 \mathrm{Nm}
\end{array}
$$

Table 1. The greatest deformation on the top floor in Structural Models I, II, III, IV and V

\begin{tabular}{|c|c|c|c|c|c|c|c|}
\hline No & Story & $\mathbf{x}(\mathbf{m})$ & $\begin{array}{c}\text { Structure } \\
\text { Model 1 } \\
\Delta_{\mathbf{1}}(\mathbf{m m})\end{array}$ & $\begin{array}{c}\text { Structure } \\
\text { Model 2 } \Delta_{\mathbf{2}} \\
(\mathbf{m m})\end{array}$ & $\begin{array}{c}\text { Structure Model 3 } \\
\Delta_{\mathbf{3}}(\mathrm{mm})\end{array}$ & $\begin{array}{c}\text { Structure Model 4 } \\
\Delta_{\mathbf{4}}(\mathrm{mm})\end{array}$ & $\begin{array}{c}\text { Structure Model 5 } \\
\Delta_{\mathbf{5}}(\mathbf{m m})\end{array}$ \\
\hline 1 & 71 & 336.5 & 467.5 & 397.6 & 381.6 & 375.3 & 396.9 \\
\hline
\end{tabular}

From the calculation results, it is proven that

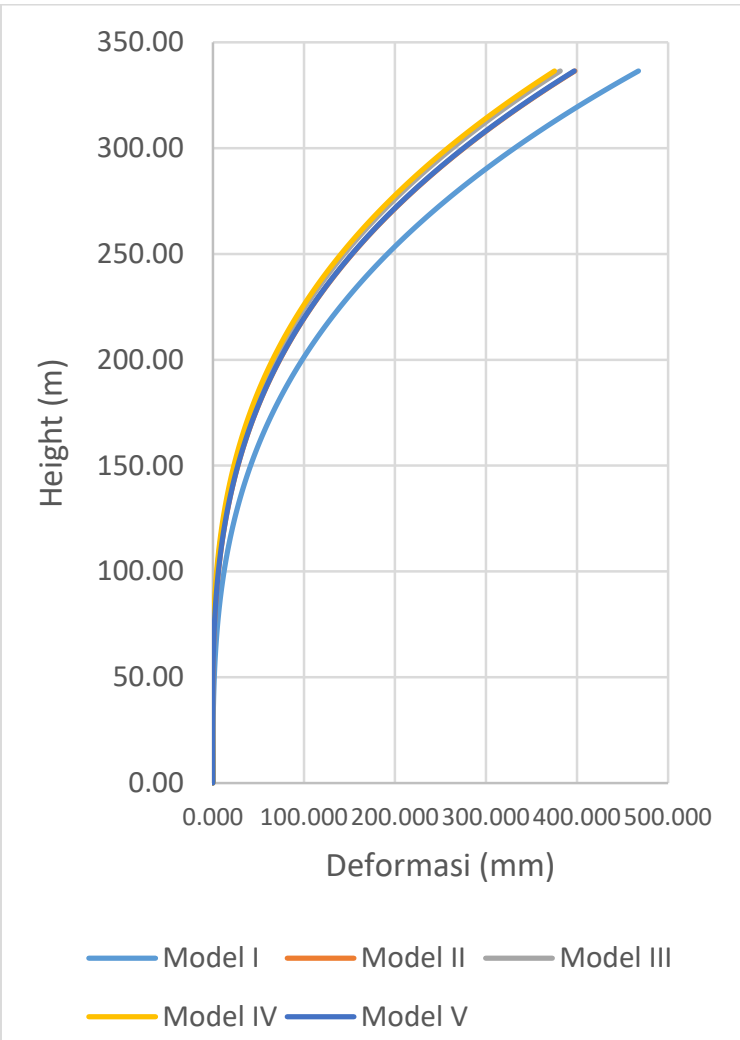
buildings using outriggers experience less deformation than buildings that do not use outriggers, it can be seen that the structure of model 1 does not use an outrigger, while for structural models II, III, IV, and V use an outrigger. Wherever the outrigger is used the result of the deformation is always smaller than it should be.The deformation reduction percentage can be calculated by:

$$
\% \Delta=\frac{\Delta^{\prime} \max -\Delta_{\max }}{\Delta^{\prime} \max } \times 100 \%
$$

Table 2. Reduced Percentage of Inter Storey Drift

\begin{tabular}{|c|c|c|c|c|}
\hline No. & $\begin{array}{c}\text { Structure } \\
\text { model }\end{array}$ & $\begin{array}{c}\Delta \text { max } \\
(\mathbf{m m})\end{array}$ & $\begin{array}{c}\Delta^{\prime} \text { max } \\
(\mathbf{m m})\end{array}$ & $\begin{array}{c}\% \Delta \\
(\%)\end{array}$ \\
\hline 1 & I & 467.523 & 467.523 & 0 \\
\hline 2 & II & 397.652 & 467.523 & 14.95 \\
\hline 3 & III & 381.581 & 467.523 & 18.38 \\
\hline 4 & IV & 375.991 & 467.523 & 19.58 \\
\hline 5 & V & 397.652 & 467.523 & 14.95 \\
\hline
\end{tabular}

\section{Inter Storey Drift}

The result inter-storey drift :

Figure 10. Deformation Results of Structural Models I, II, III, IV and V

Tabel 3. Peak Inter Storey Drifts of structure model I, II, III, IV \& V

\begin{tabular}{|c|c|c|c|c|c|c|c|}
\hline No & Story & $\mathbf{x}(\mathbf{m})$ & $\begin{array}{c}\text { ISD } \Delta_{\mathbf{1}} \\
(\mathbf{m m})\end{array}$ & $\begin{array}{c}\text { ISD } \Delta_{\mathbf{2}} \\
(\mathbf{m m})\end{array}$ & $\begin{array}{c}\text { ISD } \Delta_{\mathbf{3}} \\
(\mathbf{m m})\end{array}$ & $\begin{array}{c}\text { ISD } \Delta_{\mathbf{4}} \\
(\mathbf{m m})\end{array}$ & $\begin{array}{c}\text { ISD } \Delta_{\mathbf{5}} \\
(\mathbf{m m})\end{array}$ \\
\hline 1 & 71 & 336.5 & 19.5 & 17.5 & 17.1 & 16.9 & 17.5 \\
\hline
\end{tabular}




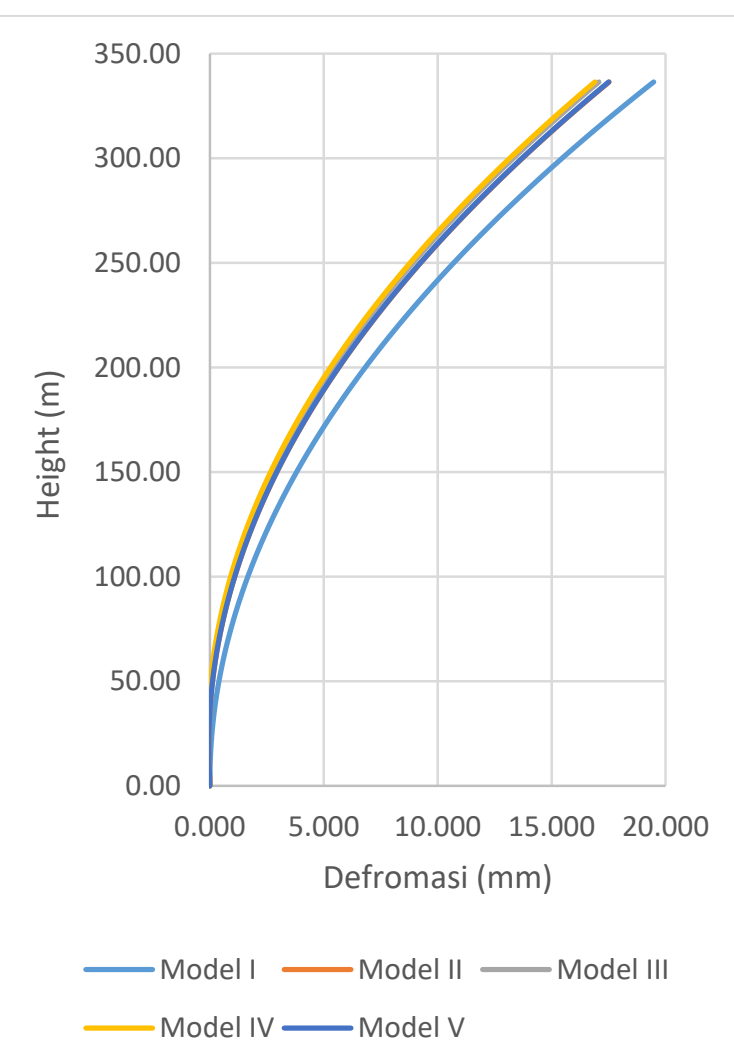

Figure 11. Inter strorey drifts structure model I, II, III, IV \& V

Inter storey drift in five building models it has been calculated and it is proven that the value of the model that does not use the outrigger is greater than the one using the outrigger.

The percentage interstory drift reduction drift is calculated by:

$$
\% I S D=\frac{I S D^{\prime} \max -I S D_{\max }}{I S D^{\prime} \max } \times 100 \%
$$

Table 4. Reduced Percentage of Inter Storey Drift

\begin{tabular}{|c|c|c|c|c|}
\hline No. & $\begin{array}{c}\text { Model } \\
\text { Struktur }\end{array}$ & $\begin{array}{c}\text { ISD max } \\
(\mathbf{m m})\end{array}$ & $\begin{array}{c}\text { ISD' max } \\
(\mathbf{m m})\end{array}$ & $\begin{array}{c}\% \\
\text { ISD } \\
(\%)\end{array}$ \\
\hline 1 & I & 19.478 & 19.478 & 0 \\
\hline 2 & II & 17.523 & 19.478 & 10.03 \\
\hline 3 & III & 17.074 & 19.478 & 12.34 \\
\hline 4 & IV & 16.898 & 19.478 & 13.24 \\
\hline 5 & V & 17.504 & 19.478 & 10.13 \\
\hline
\end{tabular}

\section{Maximum Deformation}

The peak deformation value on the building can be obtained from the $M x$ value with the equation:

$$
Y_{M}=\frac{M_{x}(L-x)(L+x)}{2 E I} .
$$

This value is only taken into account in structural models II, III, IV and V because it aims to determine the optimum location of the outrigger placement. Therefore the structural model I is not taken into account because the structural model I does not use an outrigger.

The results of the calculation of the maximum defromation are as follows :

Table 5. Deformation Calculation Results

\begin{tabular}{|c|c|c|c|c|}
\hline No. & $\begin{array}{c}\text { Structure } \\
\text { Model }\end{array}$ & floor & $\mathbf{x}(\mathbf{m})$ & $\begin{array}{c}\text { Reduction } \\
\text { of } \\
\text { Deformation } \\
(\mathbf{m m})\end{array}$ \\
\hline 1 & II & 71 & 0.000 & 69.872 \\
\hline 2 & III & 54 & 84.125 & 85.811 \\
\hline 3 & IV & 36 & 168.250 & 91.707 \\
\hline 4 & V & 18 & 252.375 & 70.308 \\
\hline
\end{tabular}

\section{Optimum Outrigger Location}

From the calculation results in (Table 5.) it can be seen that the structure model IV has the largest deformation value and it can be predicted that the optimum installation is located at $1 / 2$ the height of the building. Therefore the optimum deformation result value for the building height will be presented in the following graphic form:

\section{Optimum Outrigger Location}

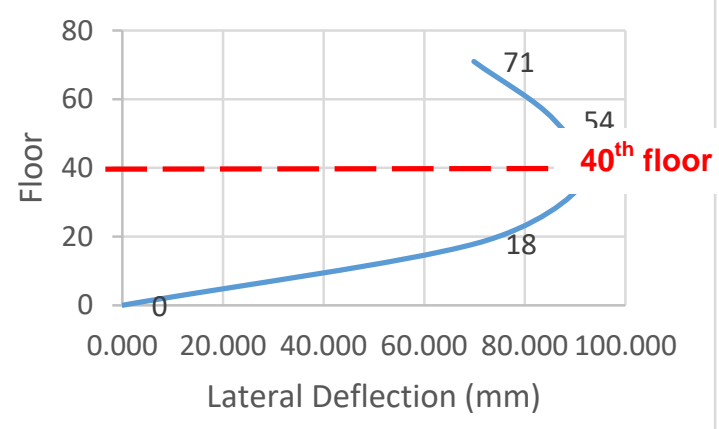

Figure12. Graph of Building Floor Defomation

From figure 12, the optimum deformation value is located on the 40th floor, namely in the model 4 structure where the installation location is located at a height of $1 / 2$ of the building height.

\section{CONCLUSION}

From the results of the wind load response analysis using the outrigger system, the following conclusions can be drawn:

1. High-rise buildings using an outrigger system can reduce lateral displacement compared to identical buildings that without outrigger. In structural model IV, the use of outrigger can reduce the highest deformation by $19.58 \%$.

2. Because the use of an outrigger can reduce deformation, it can directly reduce inter-storey drift which is considered dangerous for a highrise building. In the structure model IV, it can 
also reduce the highest inter storey drift by $13.24 \%$.

3. From the calculation of the results of the minimum deformation of the five structural models occurs in structure model IV, which is at a position $1 / 2$ of the building height and if the maximum deformation parameter is used, the optimum location of the outrigger placement is also around the middle of the building height but more precisely 40 th floor.

\section{REFERENCES}

Angerik, V. (2009). Analisis Respon Beban Angin Pada Bangunan Beton TIngkat Tinggi Yang Menggunakan Sistem Outrigger Truss. In: Laporan Tugas Akhir. Sumatra Utara: Universitas Sumatra Utara.

Choi, H., Ho, G., Joseph, L. \& Mathlas, N. (2012). Outrigger Design For High-Rise Buildings. s.I.:ILLIOIS INSTITUTE OF TECHNOLOGY.

Choi, H. S. \& Joseph, L. (2012). Outrigger System Design Considerations. Intenational journal of High-Rise Building, Volume 1, pp. 237-246.

Faimun. (2017). Studi PErbandingan Analisis Respon Spektra dan Time History Untuk Design Gedung. Jurnal Teknik ITS, Volume 6.

Goman, W. (2016). The Evaluation Of Outriggers System In Tall Buildngs, China: Tat Chee Avenue, Hongkong SAR.

Kogilgeri, S. \& Shanthapriya, B. (2015). A Study On Behaviour Of Outrigger System On High RIse Steel Structure By Varying Outrigger Depth. IRJET, 4(07).

Lam, K., Leung, M. \& Zhao, J. (2008). Interference Effects On Wind Loading Of a Row Of Closely Spaced Tall Buildings. ELSEVIER, Volume 96, pp. 562-583.

Miyashita, K., Ohkuma, T. \& Tamura, Y. (1993). Wind Induced Response Of High-Rise Buildings. ELSEVIER, Volume 50, pp. 319-328.

Pesik, R., Wallah, E. \& Handono, D. (2018). Respon Dinamis Bangunan Bertingkat BAnyak Variasi Tata Letak Outrigger. Jurnal Sipil Statik, Volume 6.

Schueller, W. (2001). Hig-Rise Building Structures. Canada: Jhon Wiley.

Taranath, B. (2012). Reinforced Concrete Design Of Tall Building. New York: Taylor and Francis Group, LLC.
W.M.Ho, G. (2017). The Evolution Of Outriggers System In Tall Building. researchgate, January.

Zhou, Y., Zhang, C. \& Lu, X. (2016). Seismic Performance of a Damping System for Tall Buildings. In: Struct. Control Health Monit. s.I.:Wiley Online Library. 